\title{
Ictericia e infección urinaria
}

\author{
DR. ERIC 'SAELZER W. *, DR. RICARDO GUZMAN *, DR. ERICH SCHILLING *
}

El diagnóstico de infección urinaria en el lactante reviste a veces gran dificultad, especialmente si la sintomatología principal está dađa por la presencia de ictericia, asociada o no a alzas térmicas o palidez.

Ya en 1928, Görter y Lignac (1) llaman la atención sobre la asociación de ictericia y pielitis en el lactante basándose en la descripción de 3 casos, uno de los cuales falleció, y en el cual la necropsia demostró signos de hepatitis y pielonefritis. Bernstein y Brown (2) reviven el problema a raíz del análisis de 70 lactantes, con hemocultivos positivos, que fallecieron de sepsis bacteriana. En el grupo estudiado les pareció relevante que en los 9 pacientes que habían presentado jctericia después de la primera semana de viđa, 7 tuvieron pielonefritis o bacilos coliformes (E. coli: 5 casos; bacilo paracolon: 2 casos). Esta observación los llevó a afirmar que todo lactante que tuvo sepsis con pielonefritis o bacilo coliforme, presentó ictericia. El estudio histológico hepático realizado post-mortem demostró alteraciones del tipo descrito como hepatitis tóxica: retención intracelular del pigmento biliar y alteraciones tóxicas de los hepatocitos. Según los autores, cstas lesiones, unidas a la presencia de una ictericia de las llamadas "por regurgitación", sugieren más bien la existencia de una hepatitis tóxica con dificultad de las células alteradas para excretar pigmento, que una obstrucción al flujo biliar.

En 1963, Hamilion y Saa-Kortsak (3) publican 24 casos de septicemia e ictericia en lactantes. En los 18 casos cn que se efectuó estudio bacteriológico de orina, el $90 \%$ (16 casos) tenía infección urinaria que, salvo 2 casos, era E. coli. Los autorcs interpretan la ictericia como originada inicialmente por un mecanismo hemolítico y

\footnotetext{
* Departamento de Gasirocnterología Infantil. Scrvitio de Pediatría, Area Occidente. Hospital San Juan de Dlos.
}

posteriormente, como consecuencia de una disfunción hepato-celular derivada de la acción tóxica de la infección. Sweet y Wolinsky (4) describen en 1964, un brote de infección a $\mathrm{E}$. coli en un Centro de Prematuros, muchos de los cuales presentaron infección urinaria e ictericia. Arthur y Wilson (5), se refreren a 4 casos de infección urinaria a bacilos coliformes ( 3 por $\mathrm{E}$. coli; 1 por paracolon) e ictericia la que interpretaron como debida a un factor obstructivo intrahepático producto de un daño celular.

En 1969 Seeler y Hahn (6) relatan 11 casos observados en el corto lapso de 11 meses. El estudio los Hlevó a cstimar que en su hospital la principal causa de ictericia en el lactante era la infección urinaria a $\mathrm{E}$. Coli. Al referirse al mecanismo de la ictericia opinan que, el factor hemolítico no constituye su única causa y que la presencia de bilirrubina directa, indicaría la posible existencia de hepatitis; agregan que podría existir una limitación del clearence de bilirrubina por alteración de la función hepática secretora.

Recientemente, $N g$ y Rawstron (7), en 1971, describen 6 casos observados en forma de brote en un período de 6 meses. Todos tenían ictericia e infección urinaria a bacilos coliformes ( 5 a $\mathbf{E}$. coli; 1 a bacilo paracolon). En 4 casos en que se practicó hemocultivo se observó el mismo germen que en el urocultivo. No efectuaron estudios histológicos. Explican la ictericia como debida a un daño hepatocelular y sugieren la posibilidad de que bacilos Gram (-) podrían producir una hepatotoxina responsable de una hepatitis tóxica y del proceso hemolítico.

En Chile, Zacarias y Cols. (8) publican la asociación de ictericia y pielonefritis en 18 prematuros, cuya ictericia se inició entre los 17 días y 41/2 meses de edad. Si bien no efectuaron hemoculitvo, 3 casos pudieron ser catalogados como sepsis sobre la base de hallazgos clínicos. El exa- 
men bacteriológico de orina en los prematuros que se estudiaron, dio Klebsiella en el $72 \%$ de los cascs y sólo en $27 \%$, E. coli. Existió variado grado de hemolisis y la actividad transaminásica del suero estuvo ligeramente elevada con valores máximos de 236 unidades. Todos los pacientes tuvieron hipssbilitrubinemia mixta con aumento relativo de la fracción conjugada. Los autores interpretan la ictericia como debida a un factor hemo'ítico $y$, en algunos casos, a relativa incapacidad de la conjugación hepática. Sugieren, además, la existencia de una falla en el mecanismo de excreción hepática por la acción de toxinas bacterianas sobre las células microciliadas que constituyen los cana!ículos biljares.

La observación de varios niños que ingresaron al Servicio de lactantes con diagnóstico de hepatitis, $y$ en los cuales el estudio clínico, de laboratorio e histopatológico mostraron, en cambio, una intensa infección del tracto urinario, nos llevó a estudiar más detenidamente la poco usual asociación entre ictericia e infección urinaria.

Materlal y MEtodo. Se estudiaron 5 lactantes cntre 2 y 6 meses de edad $(3$ sexo fem. y 2 de sexo masc.; 4 con bajo peso de nacimiento) que ingresaron con una sintomatología caracterizada por ictericia, vómitos y diversos grados de compromiso del estado general. El cuadro se había iniciado entre 3 y 30 días antes de la bospitalización. De los pacientes, 4 aparecían notoriamente pálidos y otros 4 presentaron alzas térmicas.

Todos tcnían antecedentes de vómitos y orinas oscuras; $y$, en 4 casos, de decoloración fluctuante de las deposiciones; uno solo añadía el antecedente de diarrea.

Al examen de ingreso, además de ictericia y palidez, todes presentaron hígado palpable entre 3 y $5 \mathrm{cms}$. por debajo del seborde costal en la L. M. C. Se pa'paba bazo a $1 \mathrm{~cm}$. en 4 casos y a $2 \mathrm{~cm}$. en 1 caso. En ninguno pudo observarse masa renal palpable.

Los exámenes de laboratorio revelaron la existencia de una importante anemia en todos los pacientes con hematocritos fluctuante entre $21 \mathrm{y}$ $30 \% \mathrm{y}$, con un variado grado de reticulocitosis (1 a 12\%). Todos presentaron leucocitosis variable desde 9.100 a 28.000 G. B. con desviación a izquierda en 3 casos.

El estudio de la funcionalidad hepática demostró hiperbilirrubinemias totales de 5,8 a 13,8 mgrs. $\%$, con porcentajes de la directa entre 35 y $50 \%$. Las fosfatasas alcalinas se elevaron por sobre $15 \mathrm{U}$. B. sólo en 2 casos. Las reacciones de floculación fueron negativas, excepto en un paciente. La protrombina fue normal en todos los casos. En cuanto a la actividad transaminásica oxalacética y pirúvica, estuvo elevada sobre 100 $\mathrm{U} . \mathrm{x}$ cc en sólo 2 pacientes. Se comprobó la existencia de pigmentos biliares en la orina en los dos casos en que se estudio. En 3 pacientes se efectuó hemocultivos seriados, cuyo resultado fue negativo.

El sedimento urinario mostró en los 5 enfermos piuria y leucocituria; y, el urocultivo, el desa. rrollo de más de 100.000 colonias de $\mathrm{E}$. coli sensibles a diferentes antibióticos.

Por vía percutánea, se efectuó biopsia hepática en 3 casos; ésta demostró indemnidad de la arquitectura centrolobulillar, con leve o moderada infiltración de los espacios Kiernan y leve grado de fibrosis en dos casos; la interpretación del patólogo fue la de alteraciones tóxicas hepáticas.

En los dos pacientes en que se efectuó pielografía de eliminación, ésta fue normal.

Al instaurarse terapia antibiótica, los 5 enfermos evolucionaron con mejoría de sus signos clinicos y de laboratorio, y rápida desaparición de la ictericia.

En los controles a distancia, efectuados con posterioridad al egreso de los pacientes, no se observó recidivas de la patología en cuestión.

Comentarjo. Si bien se ha descrito la aparición del sindrome que estudiamos en forma de brote (7), los 5 casos que constituyen nuestra muestra fueron observados en forma esporádica.

La sintomatología clínica no ofrece rasgos especiales y prácticamente se identifica con la hepatitis; tal vez el único signo que pudiera sugerir otra posibilidad diagnóstica, sea la palidez que en algunos casos se presenta muy pronunciada.

En todos los casos observacios se presentó coluria y decoloración parcial de las deposiciones,

TABLA No 1

HALLAXGOS CLIN/COS EN 5 LACTANTES CON ICTERICIA E INFECCION URINARIA

\begin{tabular}{lccccc}
\hline Caso & $I$ & $l l$ & $I I I$ & $I V$ & $V$ \\
\hline Edad (meses) & 2 & 6 & 2 & 3 & 3 \\
Sexo & $\mathbf{F}$ & $\mathbf{M}$ & $\mathrm{F}$ & $\mathrm{F}$ & $\mathbf{M}$ \\
Peso Nac. & 1.900 & 3.100 & 2.250 & 2.650 & 2.800 \\
Peso actual & 2.600 & 7.620 & 3.660 & 3.730 & 4.360 \\
Fiebro & - & + & + & ++ & + \\
Ictericia & $+\mathrm{a}++$ & $+\mathrm{a}++$ & +++ & + & ++ \\
Palidez & + & - & + & ++ & ++ \\
Vómitos & + & ++ & ++ & ++ & ++ \\
Diarrea & & & & & + \\
Coluria & + & + & + & + & + \\
Decolorac. & & & & & \\
$\quad$ Deposición & + & + & + & + & $?$ \\
Hígado & 4 & 5 & 4 & 3 & 4 \\
Bazo & 1 & 1 & 1 & 2 & 1 \\
Riñón & - & - & - & - & - \\
\hline
\end{tabular}


además de ictericia; ésta estaría presente según algunos autores, (10) en el 5\% de las infecciones urinarias, a expensas de ambas bilirrubinemias.

El aumento de la fracción no conjugada sería cl resultado de un mecanismo hemolítico que se manifiesta periféricamente por anemia y reticulocitosis. Algunos autores (15) han sugerido la posibilidad de que también el mecanismo de conjugación con ácido glucurónico se encuentre deprimido. La existencia de un factor hemolítico sí ha sido demostrada por Thurnan (11) al encontrar en las infecciones urinarias una mayor fragilidad de los glóbulos rojos.

EI aumento de la fracción conjugada de la bilirrubinemia, cuyo porcentaje varía entre $35 \mathrm{y}$ $50 \%$ del total, indica la existencia de un factor hepático en la génesis de la ictericia. Su mecanismo no aparece claro y se observa que la mayoría de los autores $(2,5,6,7)$ la atribuyen, tratándose de sepsis bacteriana, a hepatitis.

Ninguno de nuestros casos presenta signos de sepsis o de otra patología y los hemocultivos han sido negativos en los casos en que se practicaron. Ello permite descartar el mecanismo de hepatitis séptica como responsable de la hiperbilirrubinemia directa.
Tampoco los hallazgos de laboratorio apoyan la posibilidad de una hepatitis; tanto Jas pruebas de floculación como las protrombinemias y transaminasas fueron normales. La leve alza experimentada por éstas últimas se explica por la existencia de un proceso hemolítico concomitante (12).

La presencia de ictericia ha sido descrita, generalmente, como síntoma de septicemia con infección urinaria-pielonefritis, especialmente a $\mathrm{E}$. coli y ocasionalmente a bacilo paracolon, (1, $2,3)$.

La observación de Zacarías y cols. (8) en material de prematuros en que el $72 \%$ de los urocultivos fue a Klebsiella se aparta de lo señalado por la mayoría de los autores.

En todos nuestros casos la infección estuvo bien documentada por la presencia de piuria y un recuanto de colonias superior a $100.000 \mathrm{col}$. a bacilo coli ( $\mathrm{E}$. coli).

En la revisión de Ja literatura sobre el tema, Ilama la atención la ausencia de estudios histológicos hepáticos in vivo.

Al efectuar biopsia hepática percutánea en 3 de nuestros pacientes, su estudio histopatopatológico ha permitido descartar la presencia de una

TABLA No 2

HALLAZGOS DE LABORATORIO EN 5 LACTANTES CON ICTERICIA E INEECCION URINARIA

\begin{tabular}{|c|c|c|c|c|c|}
\hline Caso & $I$ & $l l$ & $I I I$ & $I V$ & $V$ \\
\hline Hematocrito \% & 21 & 24 & 28 & 30 & 25 \\
\hline Hemoglobina \% & 7.4 & 8.1 & 9,5 & 9,8 & 7,7 \\
\hline Reticulocitos \% & 12 & 4 & 9 & - & 5 \\
\hline Leucocitos & 28.000 & 22.900 & 9.100 & 15.800 & 16.100 \\
\hline Baciliformes $\%$ & 20 & 1 & 4 & 10 & 6 \\
\hline Bilirnubina Tot. & 6.8 & 6.6 & 13.8 & 5,8 & 9,9 \\
\hline Bilirrubina Dir. & 3.8 & 2.7 & 4,8 & 2,3 & 39 \\
\hline Fosfatasas & 2.4 & 12.9 & 24,8 & 12 & 22,4 \\
\hline Pruebas Flocul. & - & 一 & - & 一 & - \\
\hline $\begin{array}{l}\text { Pigmentos biliares } \\
\text { Urinarios }\end{array}$ & + & NI & NI & + & NI \\
\hline Protrombina \% & 100 & 100 & 100 & 65 & 100 \\
\hline \multicolumn{6}{|l|}{ Transaminasas: } \\
\hline Oa. & 165 & 19 & 116 & 94 & 50 \\
\hline Pir. & 197 & 19 & 200 & 55 & 120 \\
\hline Hemocultivo & - & 一 & 一 & & \\
\hline \multicolumn{6}{|l|}{ Orina: Sedimento } \\
\hline - Albuminuria & Ind. & 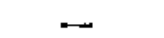 & Ind. & Ind. & 1,4 \\
\hline - Leucocitos Por C. & $8-16$ & $180-220$ & 1.2 & $7-8$ & $20-30$ \\
\hline - Glob. Pus & ++ & ++ & ++ & ++ & ++ \\
\hline \multicolumn{6}{|l|}{ Cultivo: } \\
\hline - Recuento & +100.000 & +100.000 & +100.000 & +100.000 & +100.000 \\
\hline - Germen & E. Coli & E. Coli & E. Coli & E. Coli & E. Coli \\
\hline
\end{tabular}


TA B L A No 3

HALLAZGOS HISTORATOLOGICOS EN BIOPSIAS HEPATSCAS EFECTUADAS EN LACTANTES CON ICTERICIA E INFECCION URINARIA

\begin{tabular}{|c|c|c|c|c|c|}
\hline Caso & 1 & $H$ & HIt & $I V$ & $V$ \\
\hline \multicolumn{6}{|l|}{ Arquitectura } \\
\hline Lobulillar & $\mathbf{N}$ & $\mathbf{N}$ & $\mathbf{N}$ & & \\
\hline Hepatocitos & $\mathrm{N}$ & $\mathbf{N}$ & $\mathbf{N}$ & & \\
\hline Necrosis & - & $\longrightarrow$ & $\longrightarrow$ & & \\
\hline \multicolumn{6}{|l|}{ Infiltración } \\
\hline Intralobulilar & - & 一 & 一 & & \\
\hline \multicolumn{6}{|l|}{ Infiltración } \\
\hline Periportal & Moderada & Leve & Moderada & & \\
\hline \multicolumn{6}{|l|}{ Fibrosis } \\
\hline \multirow[t]{2}{*}{ Portal } & Leve & 一 & Leve & & \\
\hline & Rencción & Reacción & Reacción & & \\
\hline Resultado & Táxico Hep. & Tóxico Hep. & Tóxico Hep. & & \\
\hline
\end{tabular}

hepatitis, observándose únicamente leves anormalidades inespecíticas, como ser infiltración celular y fibrosis escasa de los espacios porta, con absoluta indemnidad del espacio centrolobulillar y de los hepatocitos.

La ausencia de signos sepsis y de hepatitis - en el sentido del daño hepatocelular - Jleva a aceptar como mecanismo de ictericia la presencia dc una alteración funcional en los procesos de transporte y excreción del pigmento biliar ya conjugado. El mecanismo íntimo y el nivel bioquímico en que se ejerce esta acción no está claro; resulta difícil, por tanto, esbozar una hipótesis desde c! momento en que se desconoce gran parte de la fisiología normal de csta etapa del mctabolismo de la bilirrubina.

Es probable que el bacilo coli produzca algún tipo de endotoxina que actuaría enzimáticamente al nivel anteriormente señalado, bloqueando la secreción de la bilirrubina conjugada.

Orellana (9) al considerar la escasa incidencia de esta asociación, plantea otra posibilidad interesante, y es la de que en algunos individuos cxistiría un defecto congénito latente en la función excretora de la bilirrubina, que se pondría en evidencia por la acción de esta endotoxina bacteriana.

Cualquiera que sea, sin embargo, el mecanismo causal, es necesario recalcar dos hechos clínicos, que sc refieren a la importancia relativa de esta afección dontro de las ictericias del lactante, a tal punto que se la ha descrito como la primera causa de ictericia a esta edad (6); y a la necesidad de investigar en todo lactante con ictericia la posibilidad de una infección urinaria, especialmente si está asociada a palidez y cl hemograma revela anemia y leucocitosis.

\section{RESUMEN}

Se describen 5 lactantes con edades entre 2 y 6 meses que ingresaron por supuesta hepatitis, en los que el estudio urinario reveló la existencia de infección urinaria a bacilo coli.

Se discute el mecanismo etiopatológico de la ictericia, descartando la posibilidad de una hepatitis por la ansencia de signos de sepsis, normalidad bioquímica de los test que estudian la función hepática, negatividad de los hemocultivos e indemnidad histológica de las estructuras lobulillares hepáticas.

A la existencia de un componente hemolítico se sumaria un factor inhibitorio del transporte $y$ excreción del pigmento conjugado dentro de los hepatocitos, de origen tóxico bacteriano ( $E$. coli).

Se insiste en la necesidad de considerar este cuadro ante cualquier ictericia en lactantes, ya que el tratamiento oportuno de la infección urinaria determina rápida recuperación del paciente.

\section{SUMMARY}

Cases of 5 infants, from 2 to 6 month of age, hospitalized because of suspected hepatitis, in whom urise cultures revealed $\mathbf{E}$. coli bacilli infection, are described.

The physiopathology of their jaundice is discussed ruling out the possibility of hepatitis, based in:

- The abscense of septicemic signs.

- The biochemical normality of liver function tests

- Negative results of blood cultures: and

- Histological preservation of hepatic structures. 
The presence of an hemolitic factor is assumed, added to a factor inhibiting the transport an excretion of the conjugated pigunent, within the hepatic cells. This inhibiting factor should be a toxic bacterial substance (E. Coli).

The need of thinking in this entity, in any jaundice in infants is stressed, since the oportune treatment of the urinary infection results in fast recovery of the patient.

\section{REFERENCIAS}

3,-Gorter E. and Lignac, G.O.E. Arch Dis. Childh. 3; 232 (1928).

2.-Bernstein, J. and Brown, A.K. Sepsis and Jaundice in Early Infancy. Pediatrics, 29: 873, (1962).

3.-Hamilton, J.R. and Sass-Kortsak, A. Jaundice associated with severe bacterial infection in young infants. J. Pediat. 63: 121 (1963).

4.-Sweet, A.Y. and Wolinsky, E. An outbreak of urinary tract and other infections due to E. Coli. Pediatrics 33: 865 (1964).
5.-- Arthur, A.B. and Wilson, B.D.R. Urinary infection presenting with jaundice. Brit. Med. J. 1: 539 (1967).

6.-Seeler, R. A. and Hahn, K. Jaundice in urinary tract infection in infancy. Amer. J. Dis. Child. 118: 553 (1969).

7.- Ng, S.H. and Rawstron, J.R. Urinary tract infection presenting with jaundice. Arch. Dis. Child. 46: 173 (1971).

8.-Zacarias, J., Ebensperger, I., Román, C. Howard, J. Ictericia y pielonefritis en prematuros. Rev. Chil. Ped. 34: 634 (1963).

9.-Orellana, J.M. La ictericia en las infecciones por Gram negativos. Rev. Med. Chile 102: 525 (1974).

10.-Handel D. and Kitlek, W. Jaundice as chief symptom of pyuria during infancy. Deutsch Med. Wochr. 91: 1781 (1966).

11.-Thurman, W.G. Changes in red cell fragility with infections. Amer. J. Dis Child. 100: 639, (1960).

12.-Sitzman, F. C. Investigaciones sobre el comportamiento de los fermentos séricos en el R.N. con ictericia, Z.F. Kinderheilk 94: 328 (1965). 